Substance Related Exogenous Psychosis: a post-modern syndrome

Martinotti G. ${ }^{1}$, De Risio L. ${ }^{2}$, Schifano F. ${ }^{3}$, Pettorruso M. ${ }^{1}$, Vannini C. ${ }^{1}$, Di Giannantonio M. ${ }^{1}$

1. Department of Neuroscience, Imaging, Clinical Sciences, University "G.d'Annunzio", Chieti-Pescara, Italy

2. Department of Psychiatry and Addiction - ASL Roma 5 , Rome, Italy

3. Department of Pharmacy, Pharmacology, Clinical Sciences, University of Hertfordshire, Herts, UK

\title{
Post-modern society and psychopathology
}

The past two decades have been marked by dramatic social changes, widely characterized by the term "postmodern". These major transformations have had profound and complex implications for psychiatry, influencing mental health risk factors, dynamics in clinical encounters, styles of help-seeking behavior and clinical outcomes. Underlying themes of postmodern thought that are particularly relevant to psychiatry include: individualization and social roles; the nature of self-identity and intimacy; future orientation (Whitley r. 2008) 1

A defining element of post-modernity, also driven by the massive spread of signification through the Internet, is an absolute reliance on the present to the exclusion or proportional reduction of the past and future. As first described by Edmund Husserl ${ }^{2}$ and Bin Kimura ${ }^{3}$ with the notion of the presentatio or intrafaestum modality, the present is disconnected from preoccupations with the future and the past (including feelings of guilt). Contemporary adolescents and young adults are restricted to instantaneity, with loss of the ability to wait. The sociologist Oriel Sullivan's notion of 'speed-up society' echoes this general acceleration of temporal patterns ${ }^{4}$ (i.e., increase in "time intensity", feelings of "time pressure"). For instance, $\operatorname{Rosa}^{5}$ (2013) describes: acting at a faster rhythm throughout the day; getting rid of pauses or intervals between our actions; increased multitasking. In theoretical analyses of post-modern social acceleration and popularizations of the idea of the 'speed-up society' 6,7,8(e.g. Colvile, 2016; Crary, 2013; Schulte, 2014), the increasing tempo of daily life is considered central to social change. Many recent accounts of temporal acceleration are directly related to the effect of Technology (Information and Communication Technology- ICT). There have been huge changes in ICT over the past decade, and this is reflected in a growing acceleration of interconnectivity, digitalization and gaming technologies, with major effects on perceptions of time pressure.

The paradigm of liquid society, first introduced by Zygmunt Bauman ${ }^{9}$, underscores constant change, discontinuity and lack of structure in modern social life; doubt and perplexity are the only stable elements. A flame is an effective metaphorical image of this condition: an open system that constantly works to maintain an equilibrium, never evolving in an 
organized temporal structure. Meares ${ }^{10}$ argues that the existential situation of these subjects is dominated by point-events that never meet. Existence is "held hostage" by an eternal present, absorbed into immediacy, resulting in feelings of unreality and sometimes heightened excitement, anger, impulsivity. In post-modern adolescents/young adults, these emotional states are accompanied by dysphoric mood. In this context, psychoactive substances act as powerful catalysts, enhancing this a-temporal rewarding experience.

\section{Substance Use Disorders: the new scenario}

Licit and illicit psychoactive substances are cheap and easily-available to the post-modern adolescent, allowing for rapid and effortless adjustments of consciousness and emotional states to the ever-changing present. Substance use disorders (SUDs) are a major health concern: in 2010 SUDs were among the leading causes of years lived with disability worldwide [Whiteford, L. Degenhardt, 2015] ${ }^{11}$. Currently substance use is so widespread that it can be hardly defined as an aberrant behavior, although consequences are dramatic in terms of mortality and psychiatric load. As discussed by Devereux ${ }^{12}$, every society has its own norms and rules, providing the individual with different possible ways of conveying both illness/distress and success/fulfillment. In post-modern society, substance use is connected to both scenarios. Stimulants are often thought to support successful lifestyles, "empowering" and enhancing the narcissistic invulnerability that permeates certain personality structures. On the other hand, substance use typically has the effect of producing an experience of wholeness, that excludes complexity and heterogeneity in favor of the security of a single experience, thus dampening psychological distress and offsetting feelings of inadequacy and fragmentation of the self in vulnerable subjects who have difficulty coping with "speed-up". In this view, SUDs and associated psychopathology are a sort of culture-bound syndrome, profoundly rooted in the fundamentals of liquid postmodernity.

In addition to 'traditional' psychoactive substances, novel psychoactive substances (NPS) are raising increasing international concern, especially in relation to the fast-moving and potentially limitless nature of their online market (Cinosi et al., 2015; Schifano, Leoni, Martinotti, Rawaf \& Rovetto, 2003; Schifano et al., 2005; Santacroce, Corazza, Martinotti, Bersani, Valeriani \& Di Giannantonio, 2015; Martinotti et al., 2015a; Corazza et al., 2014) $13,14,15,16,17,18$. NPS have been legally defined by the European Union (EU) as new narcotic or psychotropic drugs, in pure form or preparation, that are not scheduled under the Single Convention on Narcotic Drugs of 1961 or the Convention on Psychotropic Substances of 1971 , but pose a public health threat potentially comparable to substances listed in those conventions (Council of the EU decision 2005/387/JHA) [United Nations Office on Drugs and Crime (UNODC), World Drug Report, United Nations Publication, Sales]) ${ }^{19}$. In 2017 , the total number of NPS in the EU was over 670, of which 632 were notified after 2004 
(EMCDDA, 2018). NPS are often unknown to health professionals, mainly due to lack of evidence-based sources of information (O. Corazza, S. Assi et al., 2013) ${ }^{20}$. Internet (i.e., online forums, chat rooms, blogs) has emerged as a primary source of information on drugs in general and NPS in particular. An estimated $61 \%$ of young Europeans aged 15-24 years typically quote the Internet as a source of information on drugs [Eurobarometer, Young people and drugs: analytical report, 2009, http://ec.europa.eu/public opinion/flash/fl 233 en.pdf ${ }^{21}$. Users share their experiences with different substances, and recommend sources and routes of delivery. Vulnerable young consumers are targeted by aggressive marketing strategies (i.e., attractive names, colorful packaging, free samples to test), increasing the likelihood of early exposure to substances. NPS are mostly unregulated, and this may increase their popularity as well as the flawed perception of low risks associated with use. Unfortunately, to date, few surveys on NPS diffusion have been conducted. Furthermore, there is increasing evidence that NPS use is often unintentional (Salomone, Palamar, et al 2017) ${ }^{22}$. Growing evidence supports the potential serious psychiatric and physical consequences related to NPS consumption ${ }^{23,17}$ (Simonato et al., 2013; Martinotti et al., 2015a). Originally, the most common NPS were phenethylamines and tryptamines. In recent years cathinones, synthetic cannabinoids (Spice), phencyclidine and benzofurans have gained increasing popularity (EMCDDA, Annual Report 2015) ${ }^{24}$. A number of NPS have been directly or indirectly associated with serious adverse effects and fatalities: 2DPMP and D2PM, two synthetic stimulants belonging to the class of piperidines, have shown both neuropsychiatric and cardiovascular toxicity, and have been involved in three deaths in August $2010^{25}$ (Corkery, Elliott, Schifano, et al. 2012). Misuse of gammahydroxybutyrate (GHB) and gamma-butyrolactone (GBL) has been implicated in more than 150 fatalities in the UK from 1995 to $2013{ }^{26}$ (Corkery JM, Loi B, et al., 2015) and, more recently, stimulant mixtures and synthetic cannabinoids have emerged as potentially lifethreatening ${ }^{27}$ (Santacroce et al., 2015). Moreover, the use of novel synthetic opioids is another relevant issue, with an increasing number of deaths in the US and Canada due to overdose.

NPS use is widespread among adolescents/young adults and frequent among psychiatric patients reporting psychotic symptoms at disease onset: Also, there is substantial evidence that NPS are a major risk factor for violence and aggression in patients with major mental disorders $^{28,29,30,} 31$ [Soyka, 2000; Fazel et al. 2018; Shafi A et al. 2017; Martinotti G., Cinosi E, et al 2017].

\section{Substance-Related Psychoses}

Substance use often co-occurs with schizophrenia and other psychiatric disorders. Rates of substance use disorder (SUD) among psychiatric patients are significantly higher than in the general population (up to $50 \%$ ) (Jablensky et al. 2000) ${ }^{32}$. High levels of comorbidity add to 
the diagnostic difficulties faced by clinicians and researchers in accurately differentiating substance-induced psychopathology from primary psychiatric disorders in the context of cooccurring SUD. According to the DSM-5, between $7 \%$ and $25 \%$ of first-episode psychosis subjects have a Substance-induced Psychosis (SIP) (American Psychiatric Association, 2013). Subjects with chronic and heavy substance use (cannabis, amphetamines, psychedelics, cocaine) are at highest risk. There is a growing recognition that substance use is associated with the emergence of psychosis, which develops during the use of the substance, and may or may not subside following withdrawal or abstinence. SIP subjects often call the police or ambulance and present in emergency rooms because they or family/friends feel a need for urgent intervention. Substance use, often heavy and long-term, suddenly transforms the subject's perception and/or cognition into frightening experiences that are not recognized as due to acute intoxication and require an urgent response. Some subjects may have been experiencing substance-induced psychotic phenomena for months before the symptoms motivate help-seeking. Despite this, surprisingly little research has focused on differentiating SIP from primary psychotic disorders (PP) with substance use, especially with regards to determining whether these disorders have different trajectories and outcomes (Weibell, Hegelstad, and Johannessen 2016) ${ }^{33}$. Little is known about potential factors associated specifically with SIP and the adequacy of current classification systems in appropriately distinguishing between primary and substance-induced disorders is questionable (Mathias, Lubman, and Hides 2008; Rounsaville 2007) ${ }^{34,35}$. The phenomenon of substances causing transient psychotic states was first mentioned in studies from the 1960s (Angrist and Gershon 1970) ${ }^{36}$, with several experimental studies demonstrating drug effects mimicking the positive (e.g., hallucinations, delusions, paranoia and disorganized thinking) and negative (e.g., affective flattening, anhedonia, attentional and cognitive impairment) symptoms of schizophrenia ${ }^{34}$. Current major neurobiological theories of schizophrenia have their origin in the effects of substances: the effects of lysergic acid diethylamide (LSD) gave rise to the serotonergic model; amphetamines to the dopamine hypothesis; phencyclidine (PCP) and ketamine to the glutamatergic model and, more recently, the effects of cannabis have provoked interest in the role of endocannabinoids. Numerous substances are linked to the development of psychosis and diagnoses of SIP have been included in both the International Classification of Diseases 10 (ICD-10) (World Health Organization (WHO) 1992) and the Diagnostic and Statistical Manual of Mental Disorders 5 (DSM-5) (American Psychiatric Association. 2013) ${ }^{37,38}$. The fourth edition of the DSM first introduced the term SIP in 1994. In the DSM-5, the diagnostic criteria for SIP essentially remain unchanged. SIP is defined as a condition in which psychotic symptoms (hallucinations and/or delusions) arise during or soon after substance intoxication/withdrawal and resolve within a set time period. Psychotic symptoms cannot occur exclusively during the course of a delirium. According to the DSM-5, symptoms should be more severe than those expected to occur with intoxication or withdrawal, and they should warrant the need for health care. There should be a lack of insight into 
hallucinations and delusions and symptoms should resolve within the somewhat loosely defined timeframe of "about a month" (American Psychiatric Association. 2013). ICD-10 has a slightly different and more stringent time criterion in that it requires partial resolution within 1 month and full resolution of symptoms within 6 months. In clinical practice, distinguishing between SIP and PP with concurrent substance use remains a diagnostic difficulty ${ }^{39}$ (Schanzer et al. 2006). Misdiagnoses have major implications in terms of clinical management resulting in suboptimal follow-up and inappropriate treatment, with a potentially poorer prognosis (Mathias et al., 2008) ${ }^{40}$. In the DSM, a diagnosis of SIP is based on the assumption that symptoms are transient and disappear after sustained abstinence. Literature suggests that diagnostic change over time is common: rate of change from SIP to PP ranges from 25\% to 50\% (Caton et al. 2007; Crebbin et al. 2009) ${ }^{41,42}$. A recent meta-analysis reports that SIP is associated with a substantial risk for transition to schizophrenia, particularly following cannabis-induced psychosis (Murrie et al. 2019) ${ }^{43}$. High transition rates are partly related to progression of the psychotic disorder (i.e., SIP develops into PP), and partly a result of the narrowed definition of SIP that may favor misdiagnosis (i.e., SIP diagnosed as Schizophreniform Disorder or Psychosis NOS when criteria for schizophrenia are not fulfilled) (Mathias, Lubman, and Hides 2008) ${ }^{40}$. Neither the ICD-10 nor the DSM-V allow for coding of "persistent states" of SIP, in spite of growing literature suggesting that in some chronic users psychotic symptoms can last substantially longer than the indicated timeframes (Weibell, Hegelstad, et al, 2017; Weibell, Johannessen et al 2019). ${ }^{44,45}$ The diagnosis should then be changed from SIP to PP. But even then, the question of whether chronic substance use induces a long-lasting, clinically distinct psychotic syndrome or whether it precipitates a primary psychotic disorder (i.e., schizophrenia) remains unanswered. The problem of differential diagnosis has hampered research on the specific psychopathology and the prospective outcomes of individuals with psychoses following substance use (Wilson, Szigeti et al. 2017) ${ }^{46}$. These psychotic disorders may be a separate diagnostic entity from PP that is stable over time and has distinctive psychopathological features.

In the present contribution, we aim to outline a novel and separate clinical entity, SubstanceRelated Exogenous Psychosis (SREP). As previously stated, the narrowed definition of SIP does not consider the issue of persistent psychoses that are clinically distinct from PP. Within this novel diagnostic category we refer to both transient and persistent forms of psychoses induced by substances (i.e., with onset following substance use). SREP can be considered a schizophrenia spectrum disorder but displays specific characteristics that clearly differentiate it from Schizophrenia/PP, in terms of clinical presentation, epidemiology, etiological models and treatment response.

\section{Substance Related Exogenous Psychosis: etiopathology and psychopathological models}


Epidemiological data regarding prevalence and distribution of SREP has highlighted relevant differences compared to primary psychoses. Prevalence rates of schizophrenia are similar around the world (American Psychiatric Association. 2013) ${ }^{38}$, whereas SREP typically emerges in the modern and developed world and has been mostly described in urban areas with high population density and rapid economic growth, where substance use represents a possible way to cope with 'social acceleration' and high levels of environmental stressors.

Significant differences have also been hypothesized from a psychopathological perspective. Phenomenologically-oriented researchers propose that a disturbance of the basic self is a phenotypic trait marker of psychotic vulnerability (Sass and Parnas 2003) 47. This hypothesis is based on a combination of empirical research and philosophical considerations. The type of self-disturbance proposed as being a core abnormality in schizophrenia is a pre-reflective level of selfhood (ipseity). Self-disorders become progressively more articulated and thematized as psychotic symptoms develop, crystallizing in the form of delusions, hallucinations and passivity phenomena. When substance use becomes a relevant factor in the development of a psychotic experience, this model needs to be integrated by a wider perspective. As previously discussed, a substantial number of substance users (especially if use is continuous and heavy) present persistent psychotic symptoms, opening questions regarding substance use and the development of a full, atypical chronic psychosis. In this context, the hexogen model of psychosis and its toxic subtype, defined lysergic psychoma, may be helpful in the understanding of substanceinduced phenomena. The term "lysergic psychoma" was first used by Cargnello and Callieri in 1963, though it has its roots in Hellpach's definition and in the Karl Bonhoeffer's hexogen model ${ }^{48}$. It describes a syndrome characterized by a clear egodystonic experience in which the subject perceives the presence of a "foreign body" in his mind. The thinking Ego can feel and observe it as an uncommon experience, out of control, enriched by hallucinations (mainly visual and kinesthetic), delusional perceptions and, in some cases, structured but confined delusional thoughts. The Ego is still aware and "in charge", and usually tries to suppress the psychoma.

This experience is usually transient and self-limiting, strictly connected to the pharmacodynamic effects exerted by the substance. However, repeated and heavy exposure as well as the long-lasting pharmacokinetic properties of some NPS open up a possible new scenario. When the thinking Ego has to face a recurring and intense abnormal experience (i.e., unusual thoughts or perceptions), its resilience weakens and its capacity to contain the experience fails. If the psychoma becomes stable, the capacity to offset it is progressively reduced and it invades the functioning part of the Ego. The lysergic psychoma is an exogenous clinical expression that almost all substance users experience, regardless of the substance type. Clearly, the pharmacodynamics of the drug taken is responsible for the specificity of the induced phenomena. The dopaminergic psychoma is most frequently reported as long-lasting and has the worst prognosis, as described for shaboo and 
methamphetamine users in south-eastern Asia. Methamphetamine-induced psychosis ${ }^{49}$ is, in fact, a severe form of paranoid schizophrenia, in which the psychoma has become fully pervasive. (Wearne TA et al 2018)

\section{Substance Related Exogenous Psychosis: clinical and psychopathological characteristics}

In terms of clinical presentation, SREP exhibits specific features. Descriptive studies found specific clinical characteristics that distinguish psychoses associated with substance use from schizophrenia and that may drive differential diagnosis. Caton et al. identified key demographic, family and clinical differences between SIP and PP in 400 participants with at least 1 psychotic symptom, use of alcohol and/or other drugs in the previous 30 days and no psychiatric inpatient history in the previous 6 months. ${ }^{50}$ SIP patients had more visual hallucinations, a higher prevalence of suicidal thoughts during the previous year, more violent behavior, family history of substance use and higher levels of insight. Other systematic studies aiming to characterize SIP as defined by DSM-5 and persistent, atypical psychotic disorders associated with substance use (i.e., SREP) are lacking and descriptions are mostly anecdotal. We briefly discuss possible distinctive clinical and psychopathological features associated with SREP, as reported in existing descriptive studies.

The intersection between drug intoxication and psychosis is an altered state of consciousness, with a dramatic reduction in the field of consciousness (twilight state or crepuscular consciousness). The field of consciousness is restricted to a few, or even a single content. Depersonalization or derealization are typical and reversible experiences that characterize the twilight state. The latter is often also accompanied by illusions and hallucinosis and may represent a transitory state between the transient substance-induced psychotic experience and a full-blown, persistent psychosis. Psychosis emerging from crepuscular consciousness is marked by cognitive alterations, perceptual and thought disorders, affective symptoms. When normal consciousness is restored (i.e., the fiels of consciousness widens again) it sometimes opens up to new meaning in the context of a transformed, delusional reality experience. Both quantitative and qualitative alterations of consciousness should be routinely assessed in patients with a probable alcohol/substance use. These alterations are unusual in psychiatric disorders, with the exception of dissociative disorders, frequently described in literature as substance-induced symptoms 51 (Vik, Cellucci, Jarchow \& Hedt, 2004), and may help guide early differential diagnosis. 
Modification of affectivity accompanied by depersonalization and derealization have been widely described 52,53 (G. Messas et al. 2018; Di Petta 2016). Several studies report affective symptoms (e.g., depressed mood, self-neglect and hostility) and suicidal ideation $^{54,55,56}$ (Akiyama, Saito, and Shimoda 2011; Fraser et al. 2012; Hides et al. 2015). Affective symptoms are possibly a core clinical feature of SREP and are not recognized in current diagnostic criteria ${ }^{57}$ (Voce et al. 2019).

Delusions, mostly persecutory/paranoid, are usually secondary to abnormal perception resulting from a characteristic "sensorialization" of the world and of experience ${ }^{58,53}$ (G. Messas 2013; Di Petta 2016). Messas observed these features in a population of crack users in San Paolo (Brazil) and described several fundamental elements of these psychoses, partly related to cultural and social post-modern determinants: a) hyperstability, a form of existence based on the experience of the present, cut off from the past and future; b) freezing of the sense of time, with inability to wait and invest in the future; c) hypermateriality, where the sense of space and time are condensed in the present experience; $d$ ) non-evolving, crystallized delusions, that remain condensed inside the experience of present time. These psychopathological correlates emphasize the role of substances as mediators of social drifts. These delusional experiences are unstable, in a rapid-changing on-off state, and insight is fluctuating.

Typically, intact insight has been reported as a common feature among patients with SREP 59,60, 53 (Matsumoto et al. 2002; Martinotti et al. 2015; Di Petta 2016). DSM-5 criteria consider hallucinations/delusions as symptoms of SIP only when they occur in the absence of insight and suggest that a substance user with hallucinations/delusions and insight into these should be coded as having "perceptual disturbances". However, SREP patients appear more likely to interpret symptoms as a result of substance use compared to PP patients.

Hallucinations and other perception disorders are frequently reported in SREP. Visual and cenesthetic hallucinations are more common. This is probably related to the potent interaction exerted on the $5 \mathrm{HT}$ receptors by modern hallucinogens, like MDMA and other similar compounds. In SREP, perceptual alterations probably pave the way to thought disorders. Drastic substance-induced changes of the perception-movement cycle may influence judgment. Therefore, substance-induced delusions are not primary, but secondary to intense changes and distortions of perception. Substance-induced delusions are characterized by confirmation and interpretation, not by revelation, and by fantastic contents. In line with the lysergic psychoma model, SREP delusions are similar to paraphrenic delusions, with a feeling of unreality, while the ability to analyze the feeling is preserved $^{60}$ (Martinotti et al., 2015b).

Aggressiveness appears to be transnosographic, probably representing an intrinsic element correlated with substance use. SREP patients generally have high levels of impulsivity and often display violent behavior and severe psychomotor agitation (e.g., bizarre/disorganized behavior and motor hyperactivity) ${ }^{50}$ (Caton et al. 2005). Polysubstance use has also demonstrated a strong correlation with aggression in emergency departments, together with 
higher risks of unprotected sex, car accidents, violence and victimization ${ }^{61}$ (Goldstick, Stoddard, Carter, Zimmerman, et al 2016). Positive urine drug screen results for cannabis have been associated to a higher incidence of inpatient agitation among patients admitted to a psychiatric inpatient unit with a diagnosis of schizophrenia, schizoaffective disorder or bipolar disorder ${ }^{62}$ (Johnson, Wu, Winder, et al 2016).

\section{Substance Related Exogenous Psychosis: pharmacological models of clinical presentation}

SREP can be differentiated into specific syndromes, associated with the use of different compounds. Substances may precipitate the imbalance of a wide range of neurotransmitters, pathways and receptors: dopamine (DA, mostly associated with psychedelic phenethylamines/synthetic cathinones); CB-1R activation (synthetic cannabimimetics); 5HT2A receptor activation (tryptamine derivatives/hallucinogenic plants); antagonist activities at both NMDA and mGlu2/3 receptors (PCP-like derivatives); and $\mathrm{k}$ opioid receptor activation (Salvia divinorum).

Substances mainly acting on dopaminergic pathways are primarily associated with paranoid thoughts and auditory hallucinations. Delusions of reference, persecution, grandeur and jealousy, as well as hypomanic states, are frequently reported. Aggressiveness and irritability are common, often with dysphoria, anxiety and panic episodes. With mephedrone, low mood, loss of appetite, difficulty sleeping, paranoid ideation, cognitive impairment, changes in perception, agitation, hallucinations, amnesia, confusion, violence and suicidal thoughts have been reported 63, 64,65,66,67 (Homman et al. 2018; Sullivan S, Herzig D et al., 2013; Kehr et al., 2011; Capriola, 2013; Lovrecic \& Lovrecic, 2017). Users also reported positive effects (e.g., euphoria, improved psychomotor speed, alertness, and talkativeness) 68,69,70 (Deruiter WK, Cheng et al., 2013; Dargan PI, Albert S, et al, 2010; Mdege et al., 2017). Cathinone-induced acute intoxication may include symptoms of the serotonin syndrome, such as aggression and hyperthermia, psychotic symptoms, catatonia and hyperactive delirium 71,72,73,74,75,76,77,78 (Warrick et al., 2013; Mugele et al., 2012; Hohmann et al., 2014; Denysenko et al., 2015; Otachbachi et al., 2010; Penders \& Gestring, 2011; Weaver et al., 2015; Turner J, Mitchell JL et al., 2015; Penders et al., 2012). Mood disturbances and paranoid ideation have been observed in chronic users of cathinones. Rasmon Kalayasiri's study $(2018)^{79}$ reports that up to $40 \%$ of individuals who use methamphetamine may experience psychotic symptoms or paranoia.

Consistent with their pharmacological profile, those molecules that present with high serotonin: dopamine ratios may be considered analogous to entactogenic substances, such as MDMA. Conversely, high dopamine:serotonin ratios might predict a strong stimulant experience. Furthermore, high or low affinity to modulation of noradrenergic systems might 
be associated with varying sympathetic nervous system activation, whereas activation of 5HT2A/1A receptors would more likely predict hallucinogenic effects ${ }^{80}$ (Baumeister et al., 2015).

Substances acting predominantly on serotonergic pathways are most commonly implicated in the development of visual hallucinations with vivid colors, frequently associated with intense positive or negative emotional experiences. Hallucinogens are also called 'psychedelics' (e.g., LSD) and psilocybin, 'psychotomimetics' (a term emphasizing their effects mimic psychotic symptoms) and 'entheogens' (due to the mystical-type experiences these drugs may induce). Hallucinogens may induce hallucinations, illusions and 'pseudohallucinations' (hallucinations recognized by the patient not to be the result of external stimuli), together with intense emotional responses and thoughts that may influence the human psyche ${ }^{81}$ (Schifano 2016). In order of frequency, the other possible disordered perceptions are kinesthetic and tactile. The presence of auditory, olfactory and gustatory hallucinations is uncommon. Paranoid delusions, particularly with religious content, are possible, but full-blown systematic delusions are rare. A mood alteration towards hypomanic states may be reported, although suicidal thoughts and depression states may occur as well. The predominant clinical effects of tryptamines consist in visual hallucinations, alterations in sensory perception, distortion of body image, depersonalization, marked mood lability and anxiety/panic.

Substances mainly acting on glutamatergic pathways usually determine dissociative reactions, such as derealization and somatopsychic depersonalization. Visual abnormal perception may be reported, mainly in the form of distortions and illusions. Bodily and kinesthetic hallucinations are frequent, as is the occurrence of near-death experiences. Less common are auditory, olfactory and gustatory hallucinations. Delusions with somatic themes are frequent: Ekbow, Capgras and Cotard syndromes have been reported, as well as episodes of demoniac possession and vexation. Psychotic negative symptoms are common. Mood is always flat, with affective blunting, anhedonia and a general sense of anesthesia and detachment from the surrounding environment is frequent. Irritability and aggressiveness may be noted. The 'K-hole' is an out-of-body/near-death experience, with the user becoming trapped in a state of detachment from physical presence. Residual symptoms, such as flashbacks and perceptual distortions, may follow.

Cannabis intoxication is associated with anxiety and transient psychosis-like or psychotomimetic effects that include depersonalization, derealization, ideas of reference, grandiose and paranoid delusions, flight of ideas, disorganized thinking, and auditory and visual hallucinations. Such effects have been increasingly reported with high THCcontaining strains of cannabis and synthetic cannabinoids ("spice," "K2," and "kush"), generally CB1R and CB2R full agonists.

Whilst low-dosage levels of synthetic cannabinoids produce similar psychoactive effects to cannabis/THC, with higher dosages auditory/visual hallucinations, anxiety and intense feelings of paranoia often occur ${ }^{82,83}$ (Bonaccorso et al, 2018; Winstock and Barratt, 2013a). 
Other psychiatric and neurological effects include: behavioral dyscontrol and agitation ${ }^{84}$ (Brakoulias, 2012); mood swings ${ }^{85}$ (Celofiga et al., 2014); suicidal ideation, suicide attempts; panic attacks; thought disorganization; and hyperactive delirium ${ }^{86}$ (Schifano et al., 2017). A florid/acute transient psychosis; relapse/worsening of a pre-existing psychosis and bipolar disorder ${ }^{87,88}$ (Oluwabusi et al., 2012; Ustundag et al., 2015); and persistent psychotic disorder/‘Spiceophrenia' ${ }^{89,81}$ (Papanti, Schifano, Botteon et al., 2013; Schifano et al., 2016) have all been described. Intoxication/acute toxic effects of SCs appear to be more akin to those experienced with sympathomimetic/stimulant drug use ${ }^{90,91}$ (Wood and Dargan, 2012; Naviglio et al., 2015). It is interesting to note that some SCs exhibit pharmacologically relevant affinity for psychosis-associated receptors, including D2, 5HT2A, or NMDA. Skryabin et al ${ }^{92}$ (2019) highlighted four clinical variants of SC-induced psychoses: 1. Psychosis with predominant delirium symptoms; 2. Psychosis with predominant hallucinatory symptoms; 3. Psychosis with predominant affective-delusional symptoms; 4. Psychosis with predominant mental automatism.

Substances acting on the opiate system do not usually determine clear psychotic syndromes. NSOs toxicity includes drowsiness, sedation, disorientation, slurred speech, confusion, dizziness, nausea, miosis, slowed breathing and respiratory depression ${ }^{93}$ (Suzuki and ElHaddad, 2017). Conversely, NSOs psychotropic effects include: anxiolysis; euphoria; feeling of relaxation; mood lift, dysphoric and dissociating effects 94 (Solimini et al., 2018) (Table 2). Other compounds classified among NSOs are desomorphine ('krokodil'), mitragynine and 7-Hydroxymitragynine (alkaloids found in "kratom"/Mitragyna speciose) 95 (Megan A. Rech. Et al 2014) and salvinorin A, with its analogue herkinorin, which are the main Salvia divinorum components. Salvinorin A psychoactive effects include perceptual disturbances, psychosis, irritability and anxiety.

A range of experiences may be associated with gabapentinoid high-dosage abuse, including euphoria, improved sociability, opiate-like sedation, entactogenic feelings/dissociation and psychedelic effects ${ }^{81}$ (Schifano et al., 2016).

These phenomena (serotonergic, dopaminergic and glutamatergic psychoma) cannot be considered as different syndromes, given the frequent overlap of symptoms among them. This is due to the fact that some NPS exert their effect on different pathways, and also because the possibility of polyabuse is the norm rather than the exception. However, the ability to differentiate and characterize clinical presentation may be useful to plan an appropriate therapeutic approach.

\section{Conclusion}

There is a clear need for a new diagnostic framework that provides reliable, unambiguous clinical criteria to differentiate between comorbid conditions (i.e., schizophrenia patients with SUD) and clinically distinct psychoses associated with substance use. Moreover, 
psychotic phenomena following substance use in patients with a primary diagnosis of mood (bipolar) disorder or borderline personality disorder need to be recognized and clearly distinguished from other forms of psychoses. Also, early differential diagnosis and staging between persistent psychoses associated with substance use (i.e., SREP) and transient psychotic states occurring during substance intoxication/withdrawal is necessary. In this paper we address these issues and make a first attempt to bridge this gap by discussing current literature on psychoses associated with substance use and proposing a new clinical and diagnostic entity, Substance-Related Exogenous Psychosis (SREP). SREP is conceived as a distinct psychotic disorder with its psychopathological specificities that develops following mostly chronic substance use and persists well beyond use. This distinction may have important implications for choice of treatment interventions (i.e., the contentious issue of long term antipsychotic medication in substance-related phenomena) (Dawson, et al 2008). Potent and highly rewarding NPS are frequently associated with SREP and will likely challenge and shape substance-related psychopathology for years to come. SREP is highly represented in our post-modern liquid society, marked by instantaneity and rapid transformation, where substance use is often an adaptive trait. Elements of post-modernity (i.e., instability of self-identity) dominate contemporary social contexts and possibly operate as existential background conditions that contribute to the emergence of psychotic phenomena following substance use.

\section{References}

American Psychiatric Association. 2013. Diagnostic and Statistical Manual of Mental Disorders : DSM-5 (5th Ed.).

1. Whitley r. 2008 Postmodernity and mental health. Harv Rev Psychiatry. 2008.

2. Edmund Husserl Husserl, E. 1982. Ideas Pertaining to a Pure Phenomenology and to a Phenomenological Philosophy. Dordrecht, The Netherlands: Kluwer.

3. Bin Kimura Scritti di Psicopatologia e Fenomenologia (Giovanni Fioriti, Roma 2005)

4. Speed-Up Society? Evidence from the UK 2000 and 2015 Time Use Diary Surveys; Oriel Sullivan, Jonathan Gershuny. First Published June 23, 2017 Research Article.

5. Colvile, R (2016) The Great Acceleration: How the World Is Getting Faster, Faster. New York: Bloomsbury.

6. Crary, J (2013) 24/7: Late Capitalism and the Ends of Sleep. London: Verso Books.

7. Schulte, B (2014) Overwhelmed: Work, Love and Play When No-One Has the Time. New York: Sarah Crichton Books.

8. $\operatorname{Rosa}^{7}$ (2013) Social Acceleration: A New Theory of Modernity. New York: Columbia University Press.

9. Z. Bauman Liquid Modernity 1999

10. The sense of the spirit as a form of conversation. Meares R. Asian J Psychiatr. 2012 Jun. 
11. Whiteford HA, Ferrari AJ, Degenhardt L, Feigin V, Vos T. The global burden of mental, neurological and substance use disorders: an analysis from the Global Burden of Disease Study 2010. PLoS One.

12. Devereux G. (1956) Normale e anormale. Saggi di etnopsichiatria generale (2007). Pp. 23-93. Roma. Armando Editore.

13. Cinosi $E^{1}$, Martinotti $\underline{G}^{1}$, Simonato $\underline{P}^{2}$, Singh $\underline{D}^{3}$, Demetrovics $\underline{Z}^{4}$, RomanUrrestarazu $\underline{\mathrm{A}}^{5}$, Bersani $\mathrm{FS}^{6}$, Vicknasingam B ${ }^{3}$, Piazzon $\mathrm{G}^{2}, \underline{\mathrm{Li} \mathrm{JH}}^{7}, \underline{\mathrm{Yu} \mathrm{WJ}}$, Kapitány${\underline{\text { Fövény } \mathrm{M}^{8}}}, \underline{\text { Farkas J }}^{9}$, Di Giannantonio $\mathrm{M}^{10}$, $\underline{\text { Corazza }}^{6}$. Following “The Roots" of Kratom (Mitragyna Speciosa): the evolution of an Enhancer from a Traditional Use to Increase Work and Productivity in Southeast Asia to a Recreational Psychoactive Drug in Western Countries. BioMed Research International. DOI: 10.1155/2015/968786.

14. Schifano, F., Leoni, M., Martinotti, G., Rawaf, S., \& Rovetto, F. (2003) Importance of cyberspace for the assessment of the drug abuse market: Preliminary results from the Psychonaut 2002 project. Cyberpsychology \& Behavior, 6(4), 405-410. DOI:

15. Schifano, F., Deluca, P., Agosti, L., Martinotti, G., Corkery, J. M., Alex, B., et al. (2005). New trends in the cyber and street market of recreational drugs? The case of $2 \mathrm{C}$ T-7 ('Blue Mystic'). Journal of Psychopharmacology, 19(6), 675-679.

16. Santacroce, R., Corazza, O., Martinotti, G., Bersani, F. S., Valeriani, G., \& Di Giannantonio, M. (2015). Psyclones: a roller coaster of life? Hidden synthetic cannabinoids and stimulants in apparently harmless products. Human Psychopharmacology Clinical and Experimental, 30(4), 265-71. DOI: 10.1002/hup. 2410.

17. Martinotti, G., Di Nicola, M., Quattrone, D., Santacroce, R., Schifano, F., Murray, R. et al.(2015a). Novel psychoactive substances and induced phenomena in psychopathology: the lysergic psychoma. Journal of Psychopathology, 21, 400-5.

18. Corazza, O., Valeriani, G., Bersani, F.S., Corkery, J., Martinotti, G., Bersani, G., et al. (2014). "Spice," "Kryptonite," "Black Mamba": An Overview of Brand Names and Marketing Strategies of Novel Psychoactive Substances on the Web. Journal of Psychoactive Drugs, 46(4), 287-94. DOI: 10.1080/02791072.2014.944291.

19. Council of the European Union decision 2005/387/JHA [United Nations Office on Drugs and Crime (UNODC), World Drug Report, United Nations Publication, Sales].

20. Corazza O, Assi S, Simonato P, Corkery J, Bersani FS, Demetrovics Z, Stair J, Fergus S, Pezzolesi C, Pasinetti M, Deluca P, Drummond C, Davey Z, Blaszko U, Moskalewicz J, Mervo B, Furia LD, Farre M, Flesland L, Pisarska A, Shapiro H, Siemann H, Skutle A, Sferrazza E, Torrens M, Sambola F, van der Kreeft P, Scherbaum N, Schifano F. Promoting innovation and excellence to face the rapid diffusion of novel psychoactive substances in the EU: the outcomes of the ReDNet project. Hum Psychopharmacol. 2013

21. Eurobarometer, Young people and drugs: analytical report, 2009, http://ec.europa.eu/public opinion/flash/fl 233 en.pdf].

22. Salomone A, Palamar JJ, Gerace E, Di Corcia D, Vincenti M Hair Testing for Drugs of Abuse and New Psychoactive Substances in a High-Risk Population. Anal Toxicol. 2017 Jun 1;41(5):376-381. doi: 10.1093/jat/bkx020.

23. Simonato, P., Corazza, O., Santonastaso, P., Corkery, J., Deluca, P., Davey, Z., et al. (2013). Novel psychoactive substances as a novel challenge for health professionals: results from an Italian survey. Human Psychopharmacology and Clinical Experiment, 28(4), 324-331. DOI: 10.1002/hup.2300. 
24. European Monitoring Center for Drugs and Drug Addiction-EMCDDA, Annual Report 2015.

25. 2-DPMP (desoxypipradrol, 2-benzhydrylpiperidine, 2-phenylmethylpiperidine) and D2PM (diphenyl-2-pyrrolidin-2-yl-methanol, diphenylprolinol): A preliminary review. Corkery JM, Elliott S, Schifano F, Corazza O, Ghodse AH. Prog Neuropsychopharmacol Biol Psychiatry. 2012 Dec 3;39(2):253-8

26. Corkery JM, Loi B, Claridge H, Goodair C, Corazza O, Elliott S, Schifano F. Gamma hydroxybutyrate (GHB), gamma butyrolactone (GBL) and 1,4-butanediol (1,4-BD; BDO): A literature review with a focus on UK fatalities related to non-medical use. Neurosci Biobehav Rev. 2015 Jun;53:52-78

27. Santacroce, R., Corazza, O., Martinotti, G., Bersani, F. S., Valeriani, G., \& Di Giannantonio, M. (2015). Psyclones: a roller coaster of life? Hidden synthetic cannabinoids and stimulants in apparently harmless products. Human Psychopharmacology Clinical and Experimental, 30(4), 265-71.

28. Soyka M. Substance misuse, psychiatric disorder and violent and disturbed behaviour. Br J Psychiatry. 2000 Apr;176:345-50. Review.

29. Fazel, Seena, E. Naomi Smith, Zheng Chang, and John Richard Geddes. 2018. "Risk Factors for Interpersonal Violence: An Umbrella Review of Meta-Analyses." British Journal of Psychiatry 213(4): 609-14.

30. Shafi $\mathrm{A}^{1,2}$, Gallagher $\mathrm{P}^{1}$, Stewart $\mathrm{N}^{1}$, Martinotti $\mathrm{G}^{2}$, Corazza $\mathrm{O}^{2}$. The risk of violence associated with novel psychoactive substance misuse in patients presenting to acute mental health services. Hum Psychopharmacol. 2017

31. Martinotti $G^{1,2}$, Cinosi $E^{1}$, Santacroce $\mathrm{R}^{1,2}$, Papanti $\mathrm{D}^{3}$, Pasquini $\mathrm{A}^{1}$, Mancini $\mathrm{V}^{1}$, Corbo $\mathrm{M}^{1}$, Fiori $\mathrm{F}^{1}$, Sarchione $\mathrm{F}^{1}$, Marchetti $\mathrm{D}^{4}$, Verrocchio $\mathrm{MC}^{4}$, Di Giannantonio $\mathrm{M}^{1}$, Torrens $\mathrm{M}^{5}$, Schifano $\mathrm{F}^{2}$, Morlan Coarasa $\mathrm{MJ}^{6}$, Merino Del Villar $\mathrm{C}^{6}$. Substance-related psychopathology and aggressiveness in a nightlife holiday resort: Results from a pilot study in a psychiatric inpatient unit in Ibiza. Hum Psychopharmacol. 2017

32. Jablensky A, McGrath J, Herrman H, Castle D, Gureje O, Evans M, Carr V, Morgan V, Korten A, Harvey C. Aust N Z J Psychotic disorders in urban areas: an overview of the Study on Low Prevalence Disorders. Psychiatry. 2000 Apr;34(2):221-36.

33. Weibell, Melissa A, Velden Hegelstad, and Jan Olav Johannessen. 2016. "SubstanceInduced Psychosis Substance-Induced Psychosis : Conceptual and Diagnostic Challenges in Clinical Practice." (December).

34. Mathias, Steve, Dan I Lubman, and Leanne Hides. 2008. "Substance-Induced Psychosis: A Diagnostic Conundrum." The Journal of clinical psychiatry 69(3): 358-67.

35. Rounsaville BJ 2007. DSM-V research agenda: substance abuse/psychosis comorbidity. Schizophr Bull. 2007 Jul;33(4):947-52.

36. Angrist BM and Gershon $\mathrm{S}$ The phenomenology of experimentally induced amphetamine psychosis--preliminary observations. Biol Psychiatry. 1970 Apr;2(2):95107.

37. World Health Organization (WHO) 1992. "The ICD-10 Classification of Mental and Behavioural Disorders." : 1-267.

38. Diagnostic and Statistical Manual of Mental Disorders 5 (DSM-5) ${ }^{47}$ (American Psychiatric Association. 2013)

39. Schanzer BM, First MB, Dominguez B, Hasin DS, Caton CL. Diagnosing psychotic disorders in the emergency department in the context of substance use. Psychiatr Serv. 2006 Oct;57(10):1468-73. 
40. Mathias S, Lubman DI, Hides L. Substance-induced psychosis: a diagnostic conundrum. J Clin Psychiatry. 2008 Mar;69(3):358-67. Review.

41. Caton CL, Hasin DS, Shrout PE, Drake RE, Dominguez B, First MB, Samet S, Schanzer B. Stability of early-phase primary psychotic disorders with concurrent substance use and substance-induced psychosis. Br J Psychiatry. 2007 Feb;190:105-11.

42. Crebbin K, Mitford E, Paxton R, Turkington D. First-episode drug-induced psychosis: a medium term follow up study reveals a high-risk group. Soc Psychiatry Psychiatr Epidemiol. 2009 Sep;44(9):710-5.

43. Murrie, Benjamin, Julia Lappin, Matthew Large, and Grant Sara. 2019. "Transition of Substance-Induced, Brief, and Atypical Psychoses to Schizophrenia : A Systematic Review and Meta-Analysis."

44. Weibell MA, Hegelstad WTV, Auestad B, Bramness J, Evensen J, Haahr U, Joa I, Johannessen JO, Larsen TK, Melle I, Opjordsmoen S, Rund BR, Simonsen E, Vaglum P, McGlashan T, McGorry P, Friis S. The effect of substance use on 10-year outcome in Fisrt-Episode Psychosis Schizophr Bull. 2017

45. Weibell MA, Johannessen JO, Auestad B, Bramness J, Brønnick K, Haahr U, Joa I, Larsen TK, Melle I, Opjordsmoen S, Rund BR, Røssberg JI, Simonsen E, Vaglum P, Stain H, Friis S, Hegelstad WTV. Early Substance Use Cessation Improves Cognition10 Years Outcome in First-Episode Psychosis Patients. Front Psychiatry. 2019

46. Wilson L, Szigeti A, Kearney A, Clarke M. Clinical characteristics of primary psychotic disorders with concurrent substance abuse and substance-induced psychotic disorders: A systematic review. Schizophr Res. 2018

47. Sass, Louis A, and Josef Parnas. 2003. "Schizophrenia, Consciousness, and the Self." Schizophrenia bulletin 29(3): 427-44.

48. Bonhoeffer K. (1917): Die wxogenen Reaktionstypen. ARCHIV. FÜR PSYCHIATRIE UND NERVENKRANKHEITEN, 58, Berlin

49. Wearne TA \& Cornish $\mathrm{JL}^{1}$. A Comparison of Methamphetamine-Induced Psychosis and Schizophrenia: A Review of Positive, Negative, and Cognitive Symptomatology. Front Psychiatry 2018

50. Caton CL, Drake RE, Hasin DS, et al. Differences between early-phase primary psychotic disorders with concurrent substance use and substance-induced psychoses. Arch Gen Psychiatry 2005;62:137-45.

51. Vik, P. W., Cellucci, T., Jarchow, A., \& Hedt, J. (2004). Cognitive impairment in substance abuse. Psychiatric Clinic of North America, 27(1), 97-109.

52. Messas, Guilherme, Melissa Tamelini, Milena Mancini, and Giovanni Stanghellini. 2018. "New Perspectives in Phenomenological Psychopathology : Its Use in Psychiatric Treatment."

53. Di Petta, Gilberto. 2016. Le Psicosi Sintetiche. Giovanni Fioriti Editore.

54. Akiyama K, Saito A, and Shimoda K 2011; Chronic methamphetamine psychosis after long-term abstinence in Japanese incarcerated patients. Am J Addict. 2011

55. Fraser S, Hides L, Philips L, Proctor D, Lubman DI. 2012; Differentiating first episode substance induced and primary psychotic disorders with concurrent substance use in young people. Schizophr Res. 2012 Apr;136(1-3):110-5

56. Hides L, Dawe S, McKetin R, Kavanagh DJ, Young RM, Teesson M, Saunders JB 2015 Primary and substance-induced psychotic disorders in methamphetamine users. Psychiatry Res. 2015 Mar 30;226(1):91-6. Epub 2014 Dec 18. 
57. Voce A, Burns R, Castle D, Calabria B, McKetin R.et al. 2019. Is there a discrete negative symptom syndrome in people who use methamphetamine?

Compr Psychiatry. 2019

58. Messas, Guilherme. 2013. “THE ASSOCIATION BETWEEN SUBSTANCE USE / ABUSE AND PSYCHOSIS : A PHENOMENOLOGICAL VIEWPOINT." : 2015-16.

59. Matsumoto, Toshihiko et al. 2002. "Methamphetamine in Japan: The Consequences of Methamphetamine Abuse as a Function of Route of Administration." Addiction (Abingdon, England) 97(7): 809-17.

60. Martinotti, G., Lupi, M., Carlucci, L., Cinosi, E., Santacroce, R., Acciavatti, T., et al. (2015b). Novel psychoactive substances use and knowledge among adolescents and young adults in urban and rural areas. Human Psychopharmacology and Clinical Experimental, 30(4), 295-301.

61. Goldstick JE, Stoddard SA, Carter PM, Zimmerman MA, Walton MA, Cunningham RM Characteristic substance misuse profiles among youth entering an urban emergency department: neighborhood correlates and behavioral comorbidities. Am J Drug Alcohol Abuse. 2016

62. Johnson, Wu, Winder, Casher, Marshall \& Bostwick, 2016). The Effects of Cannabis on Inpatient Agitation, Aggression, and Length of Stay. J Dual Diagn. 2016 Jul-Dec;12(34):244-251. Epub 2016 Oct 6.

63. Homman L, Seglert J, Morgan MJ. An observational study on the sub-acute effects of mephedrone on mood, cognition, sleep and physical problems in regular mephedrone users. Psychopharmacology (Berl). 2018

64. Sullivan S, Herzig D, Mohr C, Lewis G, Corcoran R, Drake R, Evans J. Theory of mind and social functioning in first episode psychosis. Cogn Neuropsychiatry. 2013 May;18(3):219-42.

65. Kehr J, Ichinose F, Yoshitake S, Goiny M, Sievertsson T, Nyberg F, Yoshitake T. Mephedrone, compared with MDMA (ecstasy) and amphetamine, rapidly increases both dopamine and 5-HT levels in nucleus accumbens of awake rats. Br J Pharmacol. 2011 Dec;164(8):1949-58.

66. Capriola M. Synthetic cathinone abuse. Clin Pharmacol. 2013 Jul 2;5:109-15.

67. Lovrecic B, Lovrecic M, Gabrovec B, Carli M, Pacini M, Maremmani AGI, Maremmani I. Non-Medical Use of Novel Synthetic Opioids: A New Challenge to Public Health. Int J Environ Res Public Health. 2019

68. Deruiter WK, Cheng C, Gehrs M, Langley J, Dewa CS. Substance abuse and smoking among a Canadian cohort of first episode psychosis patients. Community Ment Health J. 2013

69. Dargan PI, Albert S, Wood DM. Mephedrone use and associated adverse effects in school and college/university students before the UK legislation change. 2010

70. Mdege ND, Meader N, Lloyd C, Parrott S, McCambridge J. The Novel Psychoactive Substances in the UK Project: empirical and conceptual review work to produce research recommendations. Southampton (UK): NIHR Journals Library; 2017 Jun.

71. Warrick BJ, Hill M, Hekman K, Christensen R, Goetz R, Casavant MJ, Wahl M, Mowry JB, Spiller H, Anderson D, Aleguas A, Gummin D, Thomas R, Nezlek C, Smolinske S. A 9-state analysis of designer stimulant, "bath salt," hospital visits reported to poison control centers. Ann Emerg Med. 2013 Sep;62(3):244-51.

72. Mugele J, Nañagas KA, Tormoehlen LM. Serotonin syndrome associated with MDPV use: a case report. Ann Emerg Med. 2012 Jul;60(1):100-2. 
73. Hohmann N, Mikus G, Czock D. Effects and risks associated with novel psychoactive substances: mislabeling and sale as bath salts, spice, and research chemicals.Dtsch Arztebl Int. 2014 Feb 28;111(9):139-47

74. Turner J, Mitchell JL, Carroll BT, Denysenko L. Dextromethorphan /quinidine withdrawal-emergent catatonia. Ann Clin Psychiatry. 2016 May;28(2):138-9.

75. Otahbachi M, Cevik C, Bagdure S, Nugent K. Excited delirium, restraints, and unexpected death: a review of pathogenesis. Am J Forensic Med Pathol. 2010

76. Penders TM \& Gestring R, 2011; Hallucinatory delirium following use of MDPV: "Bath Salts". Gen Hosp Psychiatry. 2011 Sep-Oct;33(5):525-6.

77. Weaver MF . Prescription Sedative Misuse and Abuse. Yale J Biol Med. 2015 Sep 3;88(3):247-56. eCollection 2015 Sep. Review.

78. Penders TM, Gestring RE, Vilensky DA. Intoxication delirium following use of synthetic cathinone derivatives. Am J Drug Alcohol Abuse. 2012

79. Rasmon Kalayasiri, Kraijak K, Maes M, Mutirangura A. Methamphetamine (MA) Use Induces Specific Changes in LINE-1 Partial Methylation Patterns, Which Are Associated with MA-Induced Paranoia: a Multivariate and Neuronal Network Study. Mol Neurobiol. 2019

80. Baumeister D, Tojo LM, Tracy DK. Legal highs: staying on top of the flood of novel psychoactive substances. Ther Adv Psychopharmacol. 2015 Apr;5(2):97-132.

81. Schifano F, Papanti GD, Orsolini L, Corkery JM. Novel psychoactive substances: the pharmacology of stimulants and hallucinogens. Expert Rev Clin Pharmacol. 2016 Jul;9(7):943-54.

82. Bonaccorso S, Metastasio A, Ricciardi A, Stewart N, Jamal L, Rujully NU, Theleritis C, Ferracuti S, Ducci G, Schifano F.; Synthetic Cannabinoid use in a Case Series of Patients with Psychosis Presenting to Acute Psychiatric Settings: Clinical Presentation and Management Issues. Brain Sci. 2018 Jul 14;8(7).

83. Winstock AR and Barratt MJ, 2013a; The 12-month prevalence and nature of adverse experiences resulting in emergency medical presentations associated with the use of synthetic cannabinoid products. Hum Psychopharmacol. 2013

84. Brakoulias V, Aust N Z J; Products containing synthetic cannabinoids and psychosis. Psychiatry. 2012 Mar;46(3):281-2.

85. Celofiga A, Koprivsek J, Klavz J Use of synthetic cannabinoids in patients with psychotic disorders: case series. .J Dual Diagn. 2014.

86. Schifano F, Orsolini L, Papanti D, Corkery J. NPS: Medical Consequences Associated with Their Intake._Curr Top Behav Neurosci. 2017.

87. Oluwabusi OO, Lobach L, Akhtar U, Youngman B, Ambrosini PJ. Synthetic cannabinoid-induced psychosis: two adolescent cases. J Child Adolesc Psychopharmacol. 2012.

88. Ustundag MF, Ozhan Ibis E, Yucel A, Ozcan H. Synthetic cannabis-induced mania. Case Rep Psychiatry. 2015.

89. Papanti , Schifano F, Botteon G, Bertossi F, Mannix J, Vidoni D, Impagnatiello M, Pascolo-Fabrici E, Bonavigo T. "Spiceophrenia": a systematic overview of "spice"related psychopathological issues and a case report. Hum Psychopharmacol. 2013

90. Wood DM and Dargan PI, 2012; Novel psychoactive substances: how to understand the acute toxicity associated with the use of these substances. Ther Drug Monit. 2012

91. Naviglio S, Papanti D, Moressa V, Ventura A. An adolescent with an altered state of mind. BMJ. 2015. 
92. Skryabin VY, Vinnikova M, Nenastieva A, Alekseyuk V. Hallucinogen persisting perception disorder: A literature review and three case reports. J Addict Dis. 2019

93. Suzuki and El-Haddad. A review: Fentanyl and non-pharmaceutical fentanyls. Drug Alcohol Depend. 2017

94. Solimini R, Pichini S, Pacifici R, Busardò FP, Giorgetti R. Pharmacotoxicology of Nonfentanyl Derived New Synthetic Opioids. Front Pharmacol. 2018

95. Megan A. Rech, Elisabeth Donahey, Jacqueline M. Cappiello Dziedzic, Laura Oh, Elizabeth Greenhalgh Pharmacotherapy: The Journal of Human Pharmacology and Drug Therapy. Volume 35, Issue 2 New Drugs of Abuse, First published: 04 December 2014 